\title{
A Randomized Controlled Trial of Double Versus Triple Therapy with Amantadine for Genotype 1 Chronic Hepatitis C in Latino Patients
}

\author{
Jorge Méndez-Navarro, \\ Departamento de Gastroenterología, Hospital de Especialidades, Centro Médico Nactional Siglo \\ XXI, IMSS, Av. Cuauhtemoc 330, Col. Doctores, 06725 Mexico, DF, Mexico \\ jmndoc@yahoo.com;jmendez1@partners.org \\ Gastrointestinal Unit, Massachusetts General Hospital, Harvard Medical School, 55 Fruit Street, \\ Warren 1007, Boston, MA 02114, USA
}

\section{Ruby A. Chirino,}

Departamento de Gastroenterología, Hospital de Especialidades, Centro Médico Nactional Siglo XXI, IMSS, Av. Cuauhtemoc 330, Col. Doctores, 06725 Mexico, DF, Mexico

\section{Kathleen E. Corey,}

Gastrointestinal Unit, Massachusetts General Hospital, Harvard Medical School, 55 Fruit Street, Warren 1007, Boston, MA 02114, USA

Emmanuel C. Gorospe,

Department of Medicine, John Hopkins University School of Medicine, Baltimore, MD, USA

\section{Hui Zheng,}

MGH Biostatistics Center, Harvard Medical School, Boston, MA, USA

\section{Segundo Morá,}

Departamento de Gastroenterología, Hospital de Especialidades, Centro Médico Nactional Siglo XXI, IMSS, Av. Cuauhtemoc 330, Col. Doctores, 06725 Mexico, DF, Mexico

\section{Raymond T. Chung, and}

Gastrointestinal Unit, Massachusetts General Hospital, Harvard Medical School, 55 Fruit Street, Warren 1007, Boston, MA 02114, USA rtchung@partners.org

\section{Margarita Dehesa-Violante}

Departamento de Gastroenterología, Hospital de Especialidades, Centro Médico Nactional Siglo XXI, IMSS, Av. Cuauhtemoc 330, Col. Doctores, 06725 Mexico, DF, Mexico

\section{Abstract}

\begin{abstract}
Background-With only a third of Latinos achieving sustained virologic response (SVR), there is a need for enhanced HCV treatment. Amantadine has been proposed to improve response rates in addition to standard therapy with peginterferon a and ribavirin. Our objective is to evaluate whether triple therapy with amantadine improves SVR rates in this special population.
\end{abstract}

Method-Treatment-naíe Latino subjects with HCV genotype 1 infection were randomized to receive peginterferon [alpha]-2a plus weight-based ribavirin for 48 weeks (double therapy) or the

Conflict of Interest Statement

Margarita Dehesa-Violante, Emmanuel C. Gorospe, Ruby A. Chirino, Segundo Morán and Hui Zheng have nothing to disclose. 
same regimen plus amantadine $200 \mathrm{mg}$ daily (triple therapy). The primary endpoint was SVR. Predictors of liver fibrosis using APRI and Forns indices were also evaluated.

Results-We enrolled 124 patients with chronic hepatitis C genotype 1. Sixty-three received conventional therapy and 61 patients had triple therapy with amantadine. SVR at week 72 was achieved in 25 patients (39.7\%) vs. 26 patients (42.6\%) in the double and triple regimen, respectively $(\mathrm{p}=0.561)$. After multivariate analysis, advanced fibrosis, obesity, and low pretreatment ALT levels were associated with non-response in both groups $(\mathrm{p}=0.0234, \mathrm{p}=$ $0.0012, \mathrm{p}=0.0249$, respectively). APRI values delimited an area under the ROC curve (AUROC) of 0.724 and Forns index with AUROC of 0.733. There was no difference between both indices in predicting significant fibrosis (Knodell index: F3-F4).

Conclusion-Our study demonstrates that the addition of amantadine to standard treatment of chronic HCV does not improve SVR rates in Latino patients with genotype 1. Further research to improve response rates in this special population is needed.

\section{Keywords}

Chronic hepatitis C; Amantadine; Latino; Peginterferon; Sustained virological response

\section{Introduction}

Hepatitis C accounts for $64 \%$ of newly diagnosed chronic liver disease cases with 100,000 new hepatitis $\mathrm{C}$ cases diagnosed each year [1]. In Mexico, an estimated 1 million persons are infected $[2,3]$ with predominantly genotype 1 hepatitis C virus (HCV) [4-6]. Standard therapy for hepatitis $\mathrm{C}$ infection is pegylated interferon and ribavirin [7]. Despite major improvements in hepatitis $\mathrm{C}$ treatment, sustained virological response is achieved in $<50 \%$ of patients [8-10]. Recent evidence indicates that Latinos have lower rates of sustained virologic response rates than other ethnic groups and have a more aggressive disease course with increased risk of progression to end-stage liver disease [11-13]. Thus, Latinos represent a special population that may benefit from enhanced therapy.

Amantadine, a tricyclic amine, has antiviral activity against a broad range of viruses including influenza A virus, via its action against the target $\mathrm{M} 2$ protein $[14,15]$. The region of the HCV genome between the structural and nonstructural regions encodes a 63-amino acid membrane protein knows as $\mathrm{p} 7$, a family of viral ion channels that mediate cation fluxes across viral and cellular membranes $[15,16]$. In vitro assays demonstrate that amantadine inhibits both the M2 and p7 ion channels [14, 16-18]. The benefit of amantadine in addition to conventional therapy is uncertain $[17,19,20]$. It has been posited that the addition of the antiviral agent amantadine to standard therapy may improve response rates $[21,22]$. Conflicting evidence exists with several trials noting an improvement in SVR with triple therapy [21-23], while others suggest amantadine has no benefit [24-27].

Our study sought to evaluate whether triple therapy with amantadine improved SVR rates over conventional therapy in a naíve genotype $1 \mathrm{HCV}$ Latino population.

\section{Patients and Methods}

We identified men and women age 18-65 years with genotype $1 \mathrm{HCV}$ infection defined by the presence of an HCV antibody (second- or third-generation enzyme immunoassay), HCV RNA positive by reverse-transcription polymerase chain reaction (PCR Cobas Amplicor HCV Monitor test, version 2.0, Roche Molecular Systems, Genoma WTC, Mexico City, quantitative $<600 \mathrm{IU} / \mathrm{ml}$, qualitative $<50 \mathrm{IU} / \mathrm{ml}$ limits of detection, respectively), and genotype 1 infection (Inno-Lipa PCR, Genoma WTC, Mexico City). All patients had 
elevated serum alanine aminotransferase (ALT) levels (>=40 IU/l) for at least 6 months. Patients with cirrhosis were included only if they were Child-Pugh Class A (compensated disease). All patients were of Latino ethnicity (self-identified as "Latino or Hispanic") with Spanish as their primary language and were born in the Mexican Republic. No subject had previously been treated with interferon, peginterferon a, ribavirin, and/or amantadine. In all patients a pre-treatment liver biopsy was encouraged but not required.

Patients with other causes of liver disease, HIV infection, hepatitis B infection, end-stage renal disease, autoimmune disorders, decompensated liver disease, and complication of portal hypertension (variceal bleeding, ascites, encephalopathy, Child-Pugh B or C, hepatocellular carcinoma), hemoglobin lower than $12 \mathrm{~g} / \mathrm{dl}$, platelets $<70,000 \mathrm{plt} / \mathrm{mm} 3$, pregnancy, uncontrolled psychiatric disease, neoplastic disease, severe cardiac disease, alcohol or drug abuse, and refusal to use contraception during treatment, were excluded.

Previous literature has suggested that the addition of amantadine to standard therapy can increase SVR rates from 40 to $64 \%$ [28]. Our sample size with 63 subjects receiving double therapy and 61 subjects receiving triple therapy allows for $80 \%$ power to detect a difference of SVR between 40 and $64 \%$ with $5 \%$ type I error.

\section{Study Design}

Between March 2003 and June 2005 all eligible patients from the outpatient tertiary clinic of Gastroenterology at "Hospital de Especialidades CMN Siglo XXI, IMSS" in Mexico City, were randomized in a 1:1 fashion to one of two treatment arms: conventional double therapy with peginterferon a-2a $180 \mu \mathrm{g} /$ week (Pegasys; Roche-Syntex, Mexico City) plus 1,000-1,200 mg/day ribavirin (Copegus; Roche-Syntex, Mexico city) according to body weight $(1,000 \mathrm{mg}$ if $<75 \mathrm{~kg}$ or $1,200 \mathrm{mg}$ if $>75 \mathrm{~kg}$ ) for 48 weeks or triple therapy with the same regimen of peginterferon and ribavirin plus amantadine $200 \mathrm{mg}$ orally daily (amantadine hydrochloride $100 \mathrm{mg}$ tablets) for 48 weeks.

All patients were assessed at screening, weeks 2, 4, 8, 12, 16, 20, 24, 36, and 48 during treatment and 6 months after treatment (week 72). Hematology and biochemical tests were performed by a local laboratory. In patients without a decline in HCV RNA at week 24 treatment was discontinued. All patients who received at least one dose of medication were included in the study analysis. All patients provided written informed consent and the study was approved by the center ethics committee according to the Declaration of Helsinki.

\section{Study Endpoints}

The primary endpoint was sustained virologic response (SVR) defined as undetectable qualitative HCV RNA at the end of follow up (72 weeks). Patients in whom HCV RNA values were missing at the end of follow up were classified as nonresponders. Secondary endpoints were early virological response (EVR) defined as a $>2 \log$ reduction or undetectable HCV RNA at week 12 and the end of treatment response (EOTR) defined as an undetectable HCV RNA at week 48.

\section{Liver Biopsy}

All patients were encouraged to have a percutaneous liver biopsy before therapy to grade the histology activity index (HAI) and fibrosis stage by Knodell index [29]. Due to its simplicity, the Knodell index is the staging score used at our institution ( 0 : no fibrosis; 1 : fibrous portal expansion; 3: bridging fibrosis; 4: cirrhosis). 


\section{Fibrosis Non-invasive Index}

To evaluate for significant liver fibrosis we used two different non-invasive fibrosis indices as tools for the assessment of liver fibrosis: the AST to platelet ratio index (APRI) formula: (as described) with values of $<0.5$ or $>1.5$ for no fibrosis or significant fibrosis, respectively, and APRI values of $<1.0$ or $>2.0$ for absence or presence of cirrhosis [30], and the Forns index score system formula: [31] with cutoff values of $<4.21$ (absence) and $>6.9$ (presence) of significant fibrosis.

\section{Statistical Analysis}

Continuous variables are presented as means and standard deviation; categorical variables are shown in percentages. We used the t-test for comparison of continuous variables. For univariate comparisons of dichotomous or categorical variables we used the Chi-square test. A p-value of $<0.05$ was considered to be statistically significant. For identifi cation of independent predictors of virological response, we used multivariate logistic regression modeling. For APRI and Forns indices, receiver operating characteristics (ROC) curves were constructed to illustrate the predictive power of the independent variables for significant fibrosis (F3-F4) vs. no fibrosis. We used SAS software version 9.1.3 (SAS Institute Inc., Cary, NC) for data analysis.

\section{Results}

A total of 124 patients with chronic hepatitis $\mathrm{C}$ genotype 1 were enrolled. After randomization, 63 patients were treated with the conventional double therapy (double group) and 61 patients with triple therapy with amantadine (triple group; Fig. 1).

Patient baseline and demographic characteristics are summarized in Table 1. These characteristics were similar in both treatment groups (double vs. triple) with respect to age, gender, body mass index, pre-treatment ALT, HCV RNA, platelets and APRI or Forns index.

There was a slight predominance of women in both groups. The mean age was 46.2 years in the double group and 44 years in the triple group. The principal risk factor in both groups was history of transfusion. Most of the patients in the study were overweight (BMI 25-29.9) (mean BMI $=27.5$ ). The mean of the viral load was $976,646 \mathrm{IU} / \mathrm{ml}$ for the double group and $914,453 \mathrm{IU} / \mathrm{ml}$ for the triple group, and no significant difference in the patients with high viral load (>600,000 IU/ml) in each group. Liver biopsy was obtained in 44 of 63 patients in the double group and 52 of 61 patients in the triple group. Knodell bridging fibrosis or F3 was identified in eight and four biopsies of the double and triple group, respectively, and cirrhosis (F4) in nine patients in each group.

\section{Virologic Response}

The early virological response (EVR) obtained at 12 weeks of therapy was 68.2\% (43 patients) in the double group and $75.4 \%$ (46 patients) in the triple group ( $\mathrm{p}=0.376)$. The end of treatment response (EOTR) at 48 weeks of treatment was $58.7 \%$ (37 patients) in the double group and $57.3 \%$ (35 patients) in the triple group $(\mathrm{p}=0.879)$. Sustained virological response (SVR) was achieved in 25 patients (39.7\%) vs. 26 patients $(42.6 \%)$ in the triple regimen $(\mathrm{p}=0.561)$. There was no statistical difference in either double or triple therapy with amantadine by EVR, EOTR, or SVR rates (Fig. 2).

At the end of the follow up there were $24(38.0 \%)$ nonresponders in the double group and 26 (42.6\%) nonresponders in the triple group. The relapse rates were $22.3 \%$ (14 patients) and $14.8 \%$ (nine patients) in the double and triple group, respectively. Biochemical response, defined as normalization of ALT ( $<40 \mathrm{IU} / 1)$ at 6 months after end of treatment was similar 
in both groups (double group: 26 patients, $41.2 \%$ vs. triple group: 29 patients, $47.5 \%$ ) and was not statistically significant ( $\mathrm{p}=0.321$; Fig. 3 ).

\section{Predictors of Response}

After multivariate analysis we found obesity $(B M I>30)(p=0.0012)$, pretreatment ALT $(p$ $=0.0249)$, and significant fibrosis $(\mathrm{F} 0-\mathrm{F} 1 \mathrm{vs} . \mathrm{F} 3-\mathrm{F} 4)(\mathrm{p}=0.0234)$ inversely related to SVR.

Lower BMI and lower pre-treatment ALT were associated with higher SVR rate; also higher fibrosis ( $>1)$ was associated with a lower SVR rate. On the other hand, the viral load and double or triple therapy were not significantly related to SVR rate (Table 2).

\section{Non-invasive Fibrosis Marker Comparison}

We correlated the pre-treatment APRI and Forns with the fibrosis stage in patients with liver biopsies. For the diagnosis of significant fibrosis, APRI values delimited an area under the ROC curve (AUROC) of 0.724 and Forns index an AUROC of 0.733, indicating no meaningful difference between these methods as markers for significant fibrosis, with almost identical assessment methods for advance fibrosis (Fig. 4).

\section{Adverse Events}

The variety and frequency of adverse events were similar in both groups. Side-effects were usually mild and reversible. As a consequence of adverse events (thrombocytopenia, neutropenia, anemia), peginterferon and ribavirin had to be reduced in 19 and 13 patients, respectively, in the double group and in 14 and eight patients, respectively, in the triple group. The therapy was suspended permanently in five patients (7.9\%) in the double group and six patients (9.8\%) in the triple group. There were three patients lost to follow-up in the study (one in the double group and two in triple group). The most common adverse events observed were fatigue, myalgias, arthralgias, headache, flu-like symptoms, dry skin, nausea, and the hematological disorders describe above.

\section{Discussion}

This study was designed to determine whether triple therapy with amantadine is superior to double therapy for chronic hepatitis $\mathrm{C}$ genotype 1 infection in a Latino population. We found that triple therapy with amantadine was equivalent to double therapy in terms of tolerability and side-effects but did not demonstrate a benefit in rates of sustained virologic response.

Any difference in the virological response between the double and triple regimen could not be explained only by the baseline characteristics. After adjustment for diverse factors as pretreatment-ALT, age, viral load, BMI, fibrosis and cirrhosis the finding was consistent. Pre-treatment viral load, gender, and BMI that had been identified related to response to therapy $[7,32]$ were similar in both groups. The impact of HCV genotype in double and triple therapy was controlled by enrolling only genotype $1 \mathrm{HCV}$ patients. We also observed that factors related to therapy as the need for dose reduction, discontinuation/compliance of treatment did not explain difference in response toward one group.

These results confirm previous findings of recently published randomized trials demonstrating no benefit from the addition of amantadine to peginterferon and ribavirin in a Caucasian population [26, 27]. Our findings confirm a lack of benefit in a Latino population. In our study, the combination of Peginterferon plus ribavirin with or without amantadine reach $39-42 \%$ of sustained response, this translates to a lower SVR than published for nonLatino white patients between 45 and 55\% [13,33] but better than the African American sustained virological response of 28-30\% [34]. The racial differences in response to antiviral therapy have been attributed to diverse factors such as weight, insulin resistance, 
and socio-cultural factors $[12,35]$, but also to viral and host factors that influence the response to antiviral therapy in the form of altered viral kinetics and pharmacokinetics [36, 37]. A recent study from Ge et al. [38] identified genetic polymorphism in the IL28B gene that was associated with a two-fold difference in response to treatment among Europeans than in African- Americans patients, which can explain differences in response rates between these populations. Genetic studies in Latino patients to explore these differences are warranted.

Metabolic factors, such as obesity, steatosis, dislipide-mias, and insulin resistance, have been shown to decrease the rates of sustained response to standard treatment. Latinos have a higher prevalence of the metabolic syndrome, diabetes, and insulin resistance [12, 39], which may explain the lower response rates in this population. The multivariate analysis confirmed that some of these baseline prognostic factors are predictors of response, including fibrosis stage and BMI.

Both non-invasive fibrosis markers, APRI, and Forns could predict significant fibrosis (stages F3-F4) versus no fibrosis but we did not find that one was superior to the other for identifying advance fibrosis. Our study has several limitations. Our study sample size was based on data from Brillanti et al. [28], which found a difference in SVR rates of more than $24 \%$ between those receiving amantadine with standard therapy and those on standard therapy. Thus, we enrolled 124 subjects allowing us $80 \%$ power to detect this difference. Subsequent studies $[21,23]$ have suggested that this difference in SVR rates is smaller (7.0-12.5\%), and thus our study would have lacked sufficient power to detect such a difference.

An additional limitation is the lack of blinding in our study, which could theoretically lead to enrollment bias and alter outcomes. However, our groups were evenly matched in terms of stage of liver disease, age, BMI, and viral load, and no significant difference in response rates was seen, suggesting that the lack of blinding did not alter our results.

In conclusion, our study demonstrates that the addition of amantadine does not improve SVR in Latino patients with HCV genotype 1. Further research with nuclease/ protease and polymerase inhibitors or new strategies of treatment with the standard combination is needed for the improvement of treatment rates in this special population.

\section{Acknowledgments}

This study was performed in part with unrestricted support by Roche-Syntex SA. de CV, Mexico. We appreciate the great help of Nurse Leticia Casillas in the patients' management advocacy and her work in the database. We value the full participation of Dr. Jesus A. Juarez in this project.

Jorge Mendez-Navarro has a research scholarship from Instituto Mexicano del Seguro Social, (IMSS). Kathleen E Corey has received research support from Bristol Myers Squibb, USA. Raymond T. Chung has received research support from Roche Labs, USA.

\section{Abbreviations}

$\begin{array}{ll}\text { HCV } & \text { Hepatitis C virus } \\ \text { SVR } & \text { Sustained virological response } \\ \text { EVR } & \text { Early virological response } \\ \text { EOTR } & \text { End of treatment response } \\ \text { ULN } & \text { Upper limit of normal }\end{array}$




$\begin{array}{ll}\text { ALT } & \text { Alanine aminotransferase } \\ \text { AST } & \text { Aspartate aminotransferase } \\ \text { APRI } & \text { Aspartate aminotransferase-to-platelet ratioindex } \\ \text { ROC } & \text { Receiver operating characteristics } \\ \text { CI } & \text { Confidence interval }\end{array}$

AUROC Area under receiver operating curves

\section{References}

1. Bell BP, Manos M, Zaman A, et al. The epidemiology of newly diagnosed chronic liver disease in gastroenterology practices in the United States: results from population-based surveillance. Am J Gastroenterol. 2008; 103:2727-2736. [PubMed: 18684170]

2. Valdespino JL, Conde-Gonzalez CJ, Olaiz-Fernandez G, Palma O, Kershenobich D, Sepulveda J. Seroprevalencia de la hepatitis $\mathrm{C}$ en Adultos de México: Un problema de salud publica emer-gente? Salud Pública de México. 2007; 49:S395-S403.

3. Sanchez-Avila JF, Gonzalez E, Vazquez V, Suarez S, Uribe M. Geographical distribution of HCV genotypes in Mexico. Ann Hepatol. 2007; 6:156-160. [PubMed: 17786141]

4. Vera de leon L, Juarez-Navarro JA, Mendez-Navarro J, et al. Epidemiologic and situational panorama of hepatitis C in Mexico. Rev Gastroenterol Mex. 2005; 70:25-32. [PubMed: 16170959]

5. Dehesa-Violante M, Bosques-Padilla F, Kershenobich D. Prevalence of hepatitis C virus genotypes in Mexican patients. Rev Gastroenterol Mex. 2007; 72:344-348. [PubMed: 18595321]

6. Rivas-Estilla AM, Cordero-Perez P, Muñz-Espinosa L, et al. Genotyping of hepatitis C virus (HCV) in infected patients from northeast Mexico. Ann Hepatol. 2008; 7:144-147. [PubMed: 18626432]

7. Dienstag J, McHutchison JG. American Gastroenterological Association technical review on the management of hepatitis C. Gastroenterology. 2006; 130:231-264. [PubMed: 16401486]

8. Weigand K, Stremmel W, Encke J. Treatment of hepatitis C virus infection. World J Gastroenterol. 2007; 13:1897-1905. [PubMed: 17461488]

9. Manns MP, McHutchison JG, Gordon SC, et al. Peginterferon alfa $2 b$ plus ribavirin compared with interferon alfa $2 \mathrm{~b}$ plus ribavirin for initial treatment of chronic hepatitis $\mathrm{C}$ : a randomized trial. Lancet. 2001; 358:958-965. [PubMed: 11583749]

10. Fried MW, Shiffman ML, Reddy KR, et al. Peginterferon alfa 2a plus ribavirin for chronic hepatitis c virus infection. N Engl J Med. 2002; 347:975-982. [PubMed: 12324553]

11. Hepburn M, Hepburn L, Cantu N, Lapeer M, Lawitz E. Differences in treatment outcome for hepatitis C among ethnic groups. Am J Med. 2004; 117:163-168. [PubMed: 15276594]

12. Rodriguez-Torres M. Latinos and chronic hepatitis C: a singular population. Clin Gastroenterol Hepatol. 2008; 6:484-490. [PubMed: 18455693]

13. Rodriguez-Torres M, Jeffers L, Sheikh M, et al. Peginterferon Alfa-2a and ribavirin in Latino and non-Latino whites with Hepatitis C. N Engl J Med. 2009; 360:257-267. [PubMed: 19144941]

14. McHutchison J, Patel K. Future therapy of hepatitis C. Hepatology. 2002; 36:S245-S252. [PubMed: 12407600]

15. Clarke D, Griffin S, Beales L, et al. Evidence for the formation of a heptameric ion channel complex by the hepatitis C virus P7 protein in vitro. J Biol Chem. 2006; 281:37057-37068. [PubMed: 17032656]

16. Griffin S, St. Gelais C, Owsianka A, Patel AH, Rowlands D, Harris M. Genotype-dependent sensitivity of hepatitis C virus to inhibitors of the p7 Ion channel. Hepatology. 2008; 48:17791790. [PubMed: 18828153]

17. Steinmann E, Whitfield T, Kallis S, et al. Antiviral effects of amantadine and iminosugar derivates against hepatitis C virus. Hepatology. 2007; 46:330-338. [PubMed: 17599777]

Dig Dis Sci. Author manuscript; available in PMC 2013 August 20. 
18. Gottwein J, Scheel T, Jensen T, et al. Development and characterization of hepatitis C virus genotype 1-7 cell culture systems: role of CD81 and scavenger receptor class B type 1 and effect of antiviral drugs. Hepatology. 2009; 49:364-377. [PubMed: 19148942]

19. Berg T, Kronenberger B, Hinrichsen H, et al. Triple therapy with amantadine in treatment-naíve patients with chronic hepatitis C: a placebo controlled trial. Hepatology. 2003; 37:1359-1367. [PubMed: 12774015]

20. Deltenre P, Henrion J, Canva V, et al. Evaluation of amantadine in chronic hepatitis C: a metaanalysis. J Hepatol. 2004; 41:462-473. [PubMed: 15336450]

21. Mangia A, Minerva N, Annese M, et al. A randomized trial of amantadine and interferon versus interferon alone as initial treatment for chronic hepatitis C. Hepatology. 2001; 33:989-993. [PubMed: 11283865]

22. Uyama H, Nakamura H, Hayashi E, et al. Triple therapy of initial high-dose interferon with ribavirin and amantadine for patients with chronic hepatitis C. Hepatol Res. 2007; 37:325-330. [PubMed: 17441804]

23. Angelico M, Koehler-Host B, Piccolo P, et al. Peginterferon a-2a and ribavirin versus peginterferon a -2 a monotherapy in early virological responders and peginterferon a-2a and Ribavirin versus peginterferon a-2a, ribavirin and amantadine triple therapy in early virological nonresponders: the SMIEC II trial in naíve patients with chronic hepatitis C. Eur J Gastroenterol Hepatol. 2008; 20:680-687. [PubMed: 18679072]

24. Younossi Z, McCullough A, Barnes D, et al. Pegylated interferon a 2 b, ribavirin and amantadine for the chronic hepatitis C. Dig Dis Sci. 2005; 50:970-975. [PubMed: 15906777]

25. Angelico M, Cepparulo M, Angelico F, et al. A randomized controlled trial of amantadine plus interferon a-2a vs. interferon a-2[alpha] alone in naïve patients with chronic hepatitis $\mathrm{C}$ randomized according to the early virological response to interferon a-2a monotherapy. Aliment Pharmacol Ther. 2004; 19:339-347. [PubMed: 14984381]

26. Ferenci P, Formann E, Laferl H, et al. Randomized, double-blind, placebo-controlled study of peginterferon alfa $-2 \mathrm{a}(40 \mathrm{KD})$ plus ribavirin with or without amantadine in treatment-naíve patients with chronic hepatitis C genotype 1 infection. J Hepatol. 2006; 44:275-282. [PubMed: 16338019]

27. von Wagner M, Hofmann WP, Teuber G, et al. Placebo-controlled trial of $400 \mathrm{mg}$ amantadine combined with peginterferon alfa $2 \mathrm{a}$ and ribavirin for 48 weeks in chronic hepatitis $\mathrm{C}$ virus-1 infection. Hepatology. 2008; 48:1404-1411. [PubMed: 18846541]

28. Brillanti S, Levantesi F, Masi L, Foli M, Bolondi L. Triple antiviral therapy as a new option for patients with interferon nonresponsive chronic hepatitis C. Hepatology. 2000; 32:630-634. [PubMed: 10960460]

29. Knodell RG, Ishak KG, Black WC, et al. Formulation and application of a numerical scoring system for assessing histological activity in asymptomatic chronic active hepatitis. Hepatology. 1981; 1:431-435. [PubMed: 7308988]

30. Wai CT, Greenson J, Fontana RJ, et al. A simple noninvasive index can predict both significant fibrosis and cirrhosis in patients with chronic hepatitis C. Hepatology. 2003; 38:518-526. [PubMed: 12883497]

31. Forns X, Ampurdanes S, et al. Identification of chronic hepatitis C patients without hepatic fibrosis by a simple predictive model. Hepatology. 2002; 36:986-992. [PubMed: 12297848]

32. Ghany MG, Strader D, Thomas D, Seeff LB. Diagnosis, management and treatment of hepatitis C: an update. Hepatology. 2009; 49:1335-1374. [PubMed: 19330875]

33. Hadziyannis SJ, Sette H, Morgan TR, et al. Peginterferon alfa 2a (40 KD) plus ribavirin in chronic hepatitis C: randomized study of the effect of treatment duration and ribavirin dose. Ann Intern Med. 2004; 140:346-355. [PubMed: 14996676]

34. Conjeevaram HS, Fried MW, Jeffers LJ, et al. Peginterferon and ribavirin treatment in African American and Caucasian American patients with hepatitis C genotype 1. Gastroenterology. 2006; 131:470-477. [PubMed: 16890601]

35. Cheung RC, Currie S, Shen H, et al. Chronic hepatitis C in Latinos: natural history, treatment eligibility, acceptance and outcomes. Am J Gastroenterol. 2005; 100:2186-2193. [PubMed: 16181367] 
36. Tai AW, Chung RT. Treatment failure in Hepatitis C: mechanisms of non-response. J Hepatol. 2009; 50:412-420. [PubMed: 19070928]

37. Hoofnagle JH, Wahed AS, Brown RS, Howell CD, Belle SH. The Virahep-C Study group. Early changes in hepatitis $\mathrm{C}$ virus (HCV) levels in response to peginterferon and ribavirin treatment in patients with chronic HCV genotype 1 Infection. JID. 2009; 199:1112-1120. [PubMed: 19284286]

38. Ge D, Fellay J, Thompson A, et al. Genetic variation in IL28B predicts hepatitis C treatmentinduced viral clearance. Nature. 2009; 461:399-401. [PubMed: 19684573]

39. Romero-Gomez M, Viloria M, Andrade RJ, et al. Insulin resistance impairs sustained response rate to peginterferon plus ribavirin in chronic hepatitis C patients. Gastroenterology. 2005; 128:636641. [PubMed: 15765399] 


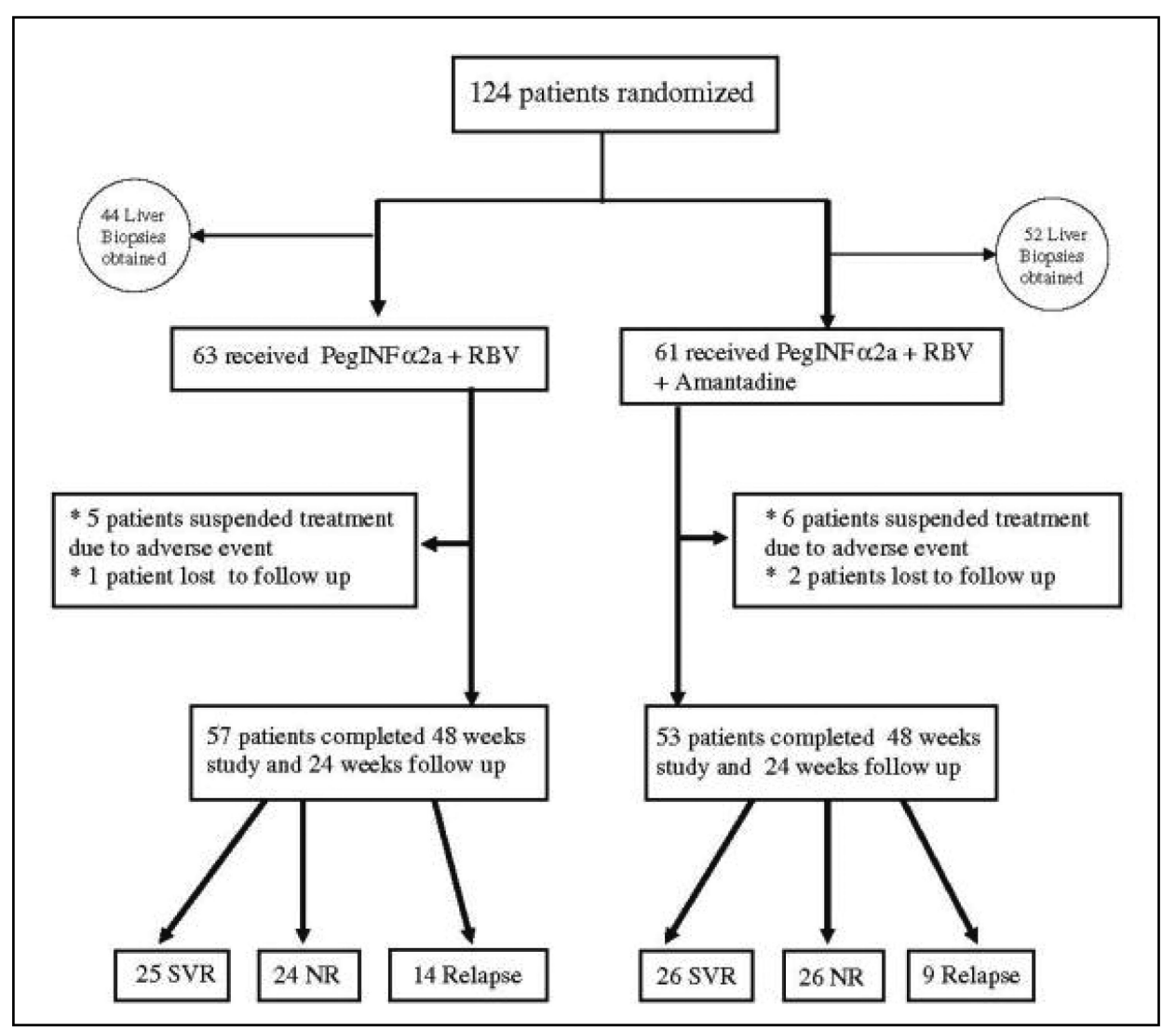

Fig. 1.

Trial profile 


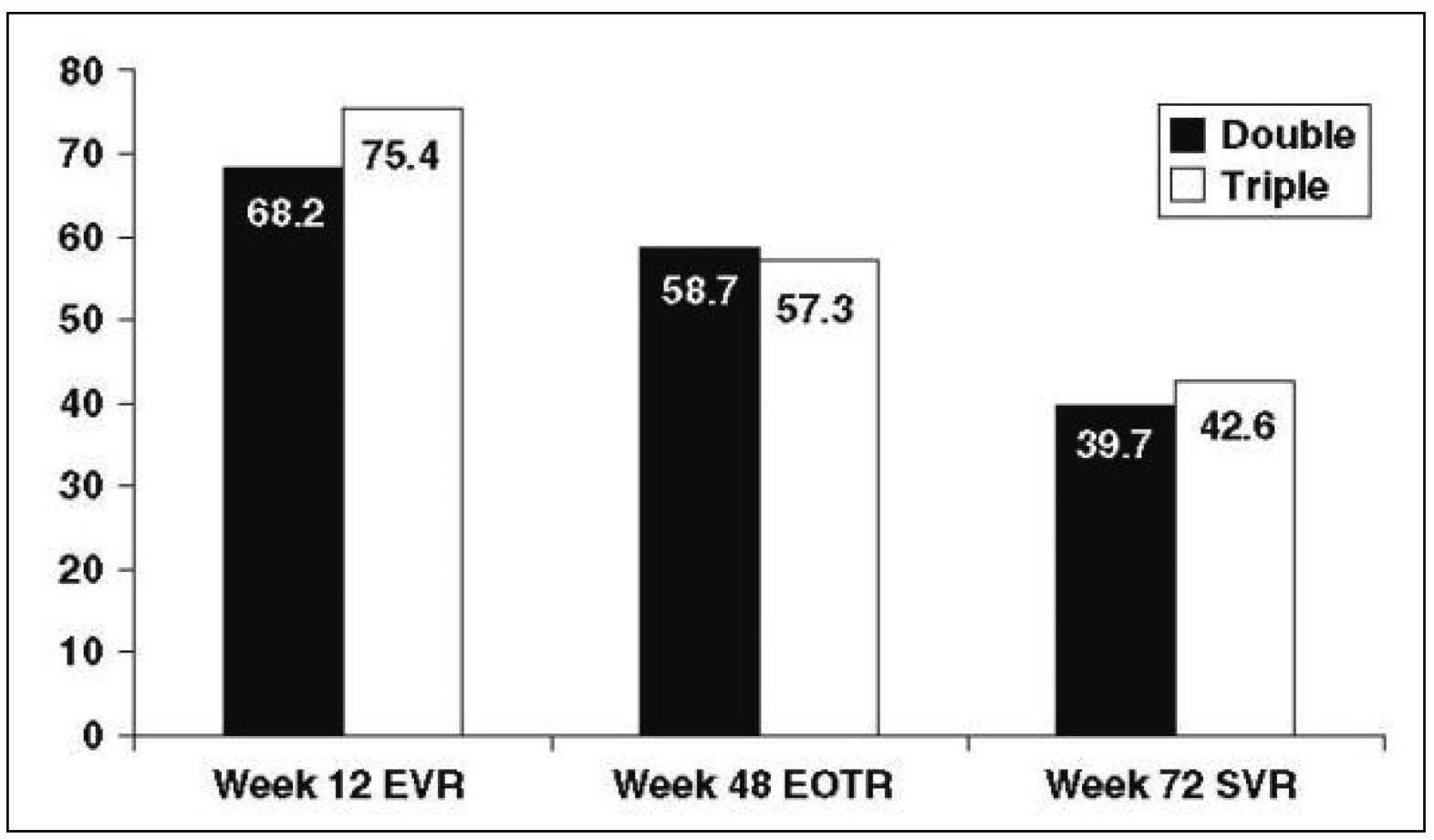

Fig. 2 .

Comparison of treatment outcomes between double and triple regimen. Double $n=63$, triple $\mathrm{n}=61$. Data expressed in percentage. EVR Early virological response on week 12, EOTR end of treatment response on week 48, SVR sustained virological response, 6 month after therapy (p-values between the double and triple group on EVR, EOTR, and SVR were $\mathrm{p}=$ $0.376,>\mathrm{p}=0.879,>\mathrm{p}=0.561$, respectively) 


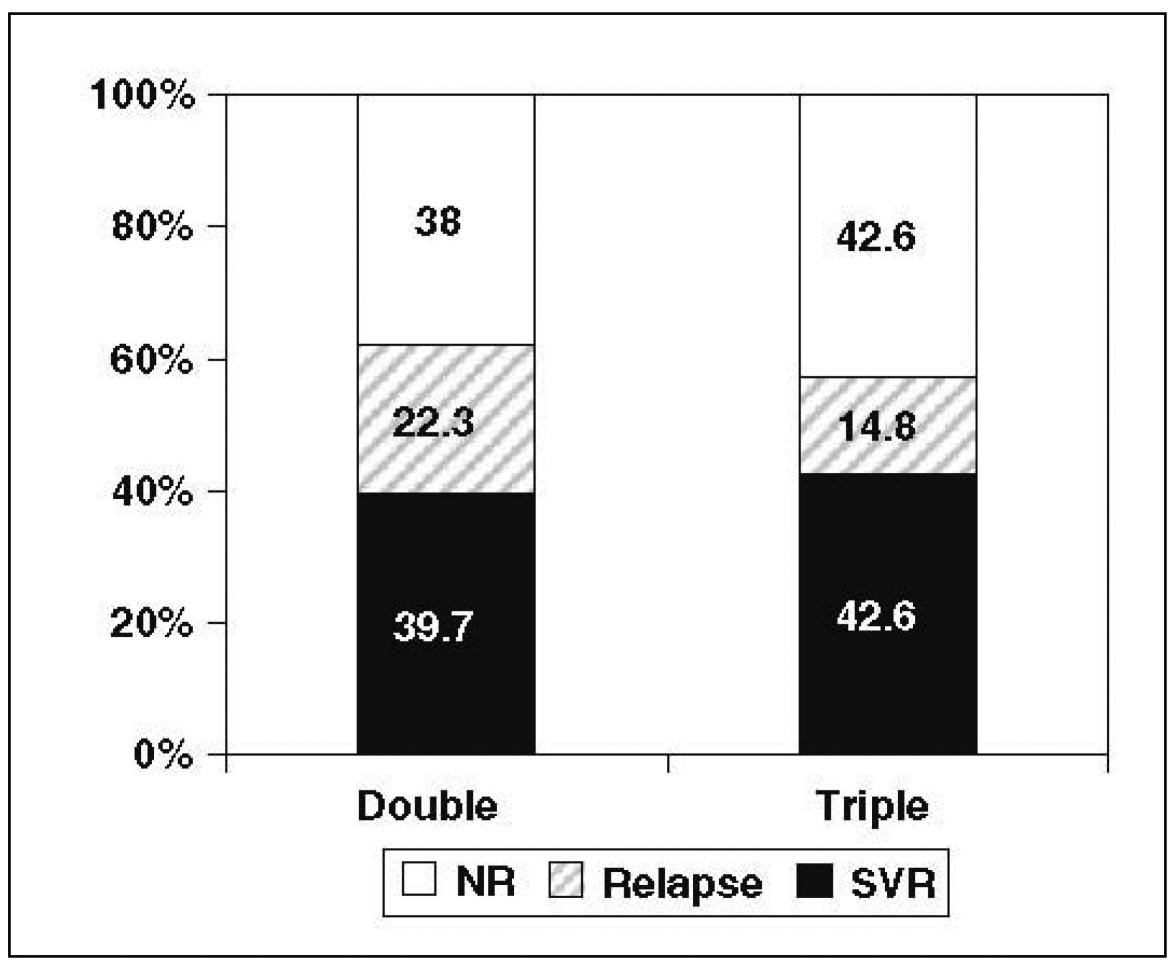

Fig. 3.

Virological outcome between the groups. The data is expressed as percentages. All patients who received at least one dose of medication were included in the study analysis. P-values for the difference between the double and triple therapy group for rates of SVR, nonresponse and relapse were $\mathrm{p}=0.561, \mathrm{p}=0.607$ and $\mathrm{p}=0.285$, respectively. NR nonresponse, SVR sustained virological response 


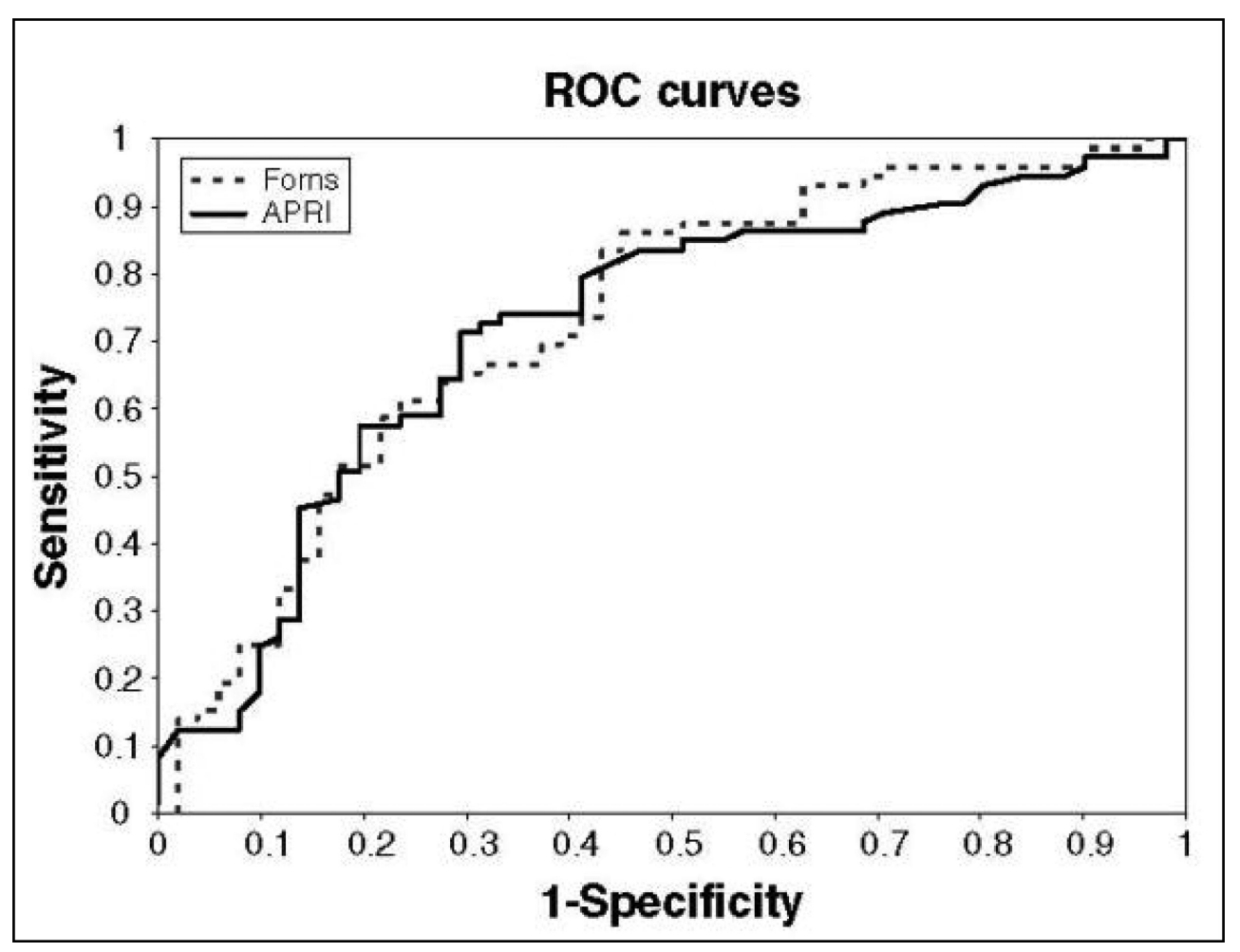

Fig. 4.

ROC for APRI and Forns indices for the prediction of significant fibrosis 
Table 1

Baseline and demographic characteristics

\begin{tabular}{llll}
\hline Baseline characteristics & Double group $\boldsymbol{n}=\mathbf{6 3}$ & Triple group $\boldsymbol{n}=\mathbf{6 1}$ & $\boldsymbol{p}$-value \\
\hline Male/female & $26 / 37$ & $29 / 32$ & \\
Age & $46.2 \pm 9.82$ & $44 \pm 12.29$ & 0.772 \\
Weight in kg & $70.41 \pm 11.49$ & $74.43 \pm 12.54$ & 0.250 \\
BMI & $27.07 \pm 3.33$ & $28.1 \pm 3.94$ & 0.236 \\
Risk factor & & & \\
$\quad$ Transfusion & 40 & 34 & \\
$\quad$ Unknown & 5 & 11 & \\
$\quad$ Intravenous drugs & 2 & 0 & \\
$\quad$ Prolonged surgery & & \\
$\quad$ Health care worker & 15 & 14 & 0.512 \\
ALT pre-treatment IU/L & $117.09 \pm 76.59$ & 1 & 0.356 \\
Platelets cell/mm ${ }^{3}$ & $163.18 \pm 75.2$ & $211.91 \pm 77.09$ & 0.325 \\
Total Bilirubin mg/dl & $0.99 \pm 0.56$ & $0.91 \pm 0.47$ & 0.476 \\
Albumin g/dl & $4.10 \pm 0.36$ & $4.15 \pm 0.34$ & 0.297 \\
Viral load IU/ml & $976.646 \pm 1,515.202 .66$ & $914.453 \pm 1,256.796$ & 0.292 \\
Low VL < 600,000 IU/ml & 38 & 37 & \\
HighVL > 600,000 IU/ml & 25 & 24 & \\
APRI score & $1.899 \pm 1.58$ & $1.271 \pm 1.35$ & \\
Forns index & $6.807 \pm 3.13$ & $4.920 \pm 2.94$ & \\
Knodell fibrosis score F3 & $8(n=44)^{b}$ & $4(n=52)^{b}$ & \\
Knodell fibrosis F4 & $9(n=44)^{b}$ & $9(n=52)^{b}$ & \\
\hline & & & \\
\hline
\end{tabular}

Data are expressed as mean \pm standard deviation (SD) and/or absolute numbers, Chi-square test

$V L$ viral load; $B M I$ body mass index = the weight in kilograms divided by the square of height in meters

a Prolonged surgery: reported as more than $4 \mathrm{~h}$ operating room surgery with unknown of transfusion during that surgery before 1994

$b_{\text {Number of patients per group with a liver biospy result }}$ 


\section{Table 2}

Multivariate analysis of baseline prognostic factors for the prediction of sustained virologic response (SVR)

\begin{tabular}{llll}
\hline Parameter & Odds ratio estimate for SVR & 95\% confidence interval & $\boldsymbol{p}$-value \\
\hline BMI $25-29$ vs. 230 & 8.048 & $(1.993-32.491)$ & 0.0012 \\
ALT $\$ 80$ vs. $>80$ & 3.491 & $(1.171-10.405)$ & 0.0249 \\
High viral load vs. low VL & 1.487 & $(0.586-3.772)$ & 0.4385 \\
Fibrosis F3-F4 vs. F0-F1 $^{a}$ & 0.255 & $(0.078-0.831)$ & 0.0234 \\
Treatment, double vs. triple & 1.781 & $(0.693-4.578)$ & 0.2311 \\
\hline
\end{tabular}

Multivariate logistic regression model and Chi-square

Body mass index $(\mathrm{BMI})=$ the weight in kilograms divided by the square of height in meters. BMI $\geq 30=$ Obesity. VL $=$ Viral load, High VL $=\geq$ $600,000 \mathrm{IU} / \mathrm{ml}$

${ }^{a}$ Patients with a liver biopsy result $(n=96)$ 